\title{
Is the fear of malignancy in large adrenal masses realistic?
}

\author{
Bartu Badak $\odot$, Erhan Aslaner $\odot$ \\ Department of General Surgery, Eskişehir Osmangazi University School of Medicine, Eskişehir, Turkey
}

\begin{abstract}
Objectives: Adrenal masses are more frequently detected in autopsy series in recent years and are more frequently detected in clinical practice due to the development of radiological examinations. After the detection of an adrenal mass, the first two important questions come to mind. Does the mass hormonally active (functionally) or not active (non-functional), and this mass is a benign formation or is it malignant? The answer to these two questions is the obligatory questions that clinicians must answer in order to make an operation decision. The decision of operation in non-functioning adrenal masses is directly proportional to the mass's neoplastic potential. If a preoperative histopathological diagnosis is not available; this potential is predicted by the size of the mass in radiological imaging. It is shown that the malignancy rate in adrenal masses is higher in lesions $6 \mathrm{~cm}$ and above. In this study, we aimed to determine whether the rate of malignancy is really high in histopathological examination as a result of adrenalectomy operations performed in our clinic between the years of 2010-2012.
\end{abstract}

Methods: Fourteen women and 4 men with $6 \mathrm{~cm}$ or higher adrenal masses patients which performed adrenalectomy by Eskişehir Osmangazi University Faculty of Medicine Department of General Surgery between 2010-2012 were included in this study. The results of the final histopathological analysis were classified retrospectively.

Results: The rate of malignancy in adrenal masses of $6 \mathrm{~cm}$ or more supported by the literature was found to be high in our clinical series.

Conclusions: As a result of our clinical retrospective study, we think that the extent of the formation in the related gland is highly effective and significant in making an operation decision before adrenalectomy.

Keywords: Adrenal, mass, surgery

A drenal glands are located upper side of both kidneys, which plays an important role of water and electrolyte balance in body metabolism. It is the main organ in the body's stress response due to hormones it secretes. Although the incidence of adrenal masses is increasing in autopsy series, their incidence reaches peak levels in the fifth decades. Although many adrenal masses do not cause clinical symptoms and do not cause any health problems, adrenal gland-borne diseases have mainly high clinical value such as Cushing, Conn, Addison, Pheochromocytoma, and have long- term follow-up. Adrenal masses that have been detected during radiological examinations for another reason and which are not known before are called adrenal insidentilomas [1]. In order for this definition to gain value, the patient should not be aware of the presence of an adrenal disease and the patient should not be followed for oncological reasons. In recent years, the incidence of adrenal insidentilomas has increased with the development of radiological examinations and equipment. When any adrenal mass is encountered, two important questions come to mind. The first 
is whether this mass is hormoneally active (functionalnonfunctional), and the second is whether this mass is malignant or benign. These benign and malign lesions include adenomas, myolipomas, ganglioneuromas, pheochromocytoma, cysts, hematomas, adrenocortical cancers and metastases. Cancers among these causes of incidentiloma have a significant mortality rate. Therefore, it is critical to establish the presence of malignancy. The feature of the mass which is thought to increase the prevalence of malignancy in adrenal masses revealed by the studies, stands out as 'dimension'. This rate is $2 \%$ in tumors less than $4 \mathrm{~cm}, 6 \%$ in 4-6 cm, and 20\% in masses over $6 \mathrm{~cm} \mathrm{[2].} \mathrm{In} \mathrm{this}$ study, we tried to show the realism of malignancy rate in these masses of $6 \mathrm{~cm}$ or more in adrenalectomies performed in our clinic for 2 years.

\section{METHODS}

Between January 2010 and December 2012, we included 18 cases of adrenal insidentiloma of $6 \mathrm{~cm}$ and over performed by Eskişehir Osmangazi University general surgery department. There was no previous history of malignancy or history of the adrenal gland. Insidentilomas detected in each patient after tomography or abdominal pain for the patients who applied to our clinic. Fourteen patients were female and 4 were male and the mean age was $50 \pm 2$ years. A detailed medical history was obtained from all patients before the surgery and detailed physical examinations were performed. Serum cortisol, aldosterone, dehydroepiandrostenedione sulfate levels, free cortisol, vanilla mandelic acid, metanephrine levels in the urine were studied in patients with a known pre-operative adrenal-derived hormone active disease required for routine blood count and biochemical parameters. Upper abdominal computed tomography was performed in all patients. Some patients $(n=8)$ received support from dynamic adrenal computed tomography.

\section{RESULTS}

When the histopathological results of 18 adrenalectomy cases included in the study were evaluated; there were 8 adrenal adenomas, 4 adrenal cysts, 1 lymphangioma, 1 hemangioma, 2 adrenal carcinoma and two adrenal oncocytic tumors (Table 1). Four (22.2\%) of 18 adrenalectomy cases had malignant potential. Under these data, a malignancy rate of $22.2 \%$ was observed in patients who were operated due to an adrenal mass of $6 \mathrm{~cm}$ or more. When the literature was examined, it was observed that the rate of frightening malignancy up to $20 \%$ was realistic in the masses of $6 \mathrm{~cm}$ and above and that this rate was present in our clinical practice. In the evaluation of the difference between the two ratios, two ratio tests were performed and no difference was found $(p=0.815)$.

\section{Table 1. The histopathological results of 18 adrenalectomy cases}

\begin{tabular}{lcc}
\hline Diagnosis & Number (n) & Percent (\%) \\
\hline Adenoma & 8 & 44.4 \\
Cyst & 4 & 22.2 \\
Carcinoma & 2 & 11.1 \\
Oncocytic tumor & 2 & 11.1 \\
Hemangioma & 1 & 5.55 \\
Lymphangioma & 1 & 5.55 \\
\hline
\end{tabular}

\section{DISCUSSION}

In recent years, with the development of radiological techniques, an increase in the incidence of adrenal masses and an increasing number of operations for these masses are striking. Adrenal insidentiloma is a condition that is detected during screening for other reasons in patients who have unknown adrenal origin disease and who are not followed-up for any oncologic process [3]. Although the ratio of adrenal masses is 1.2-1.3 for gender (Female/Male), the mean age group is between 5 and 6 decades. In our study, the patient portfolio was found to be compatible with the age of occurrence, but inconsistent with respect to the ratio of men and women (14 females-4 males, mean age: $50 \pm 2$ years) [4].

Adrenal masses are usually in benign behavior (94\%) and hormonal inactive (90\%) and most of them do not show clinical findings. It has also been shown that approximately $80 \%$ of these masses are smaller than $2 \mathrm{~cm}$ in size. However, when any adrenal mass is encountered, there are two critical questions that must be answered before the operation decision. The first of these; whether the mass is hormonal active or not. 
Second, the question is whether this mass is benign or malignant. If there is a suspicious histopathological examination before the operation, this option will lead to the operation. If the mass is hormonal active, the operation should be decided after the necessary preparations. However, in case of a mass that does not have a hormonal inactive and histopathological verification, the decision should be made acording to the malignancy potential of the mass [5]. Based on the available information, the only parameter available to evaluate the malignancy potential of an hormonal inactive adrenal mass is the size of the parameter. It is thought that as the size of an adrenal mass increases, the potential of malignancy increases. While the malignancy rate is $2 \%$ for masses smaller than $4 \mathrm{~cm}$ masses, $6 \%$ in the masses between 4-6 $\mathrm{cm}$ and $20 \%$ in the masses larger than $6 \mathrm{~cm} \mathrm{[6].}$

The most commonly used method for imaging adrenal masses is abdominal computed tomography (CT). Ultrasonography and magnetic resonance imaging (MRI) are also frequently used imaging methods. We preferred CT as the imaging method in all of our cases. Fine needle aspiration biopsy (FNAB) may be used in the evaluation of insidentilomas in some centers. However, false negative rates and complications may occur in approximately $40 \%$ of these cases [7]. There is no standard surgical procedure for adrenal masses, but laparoscopic adrenalectomy is a minimally invasive surgical technique. Laparoscopy is the gold standard in the surgical treatment of benign adrenal masses. Laparoscopy and open surgery should be decided by considering the relationship of the mass with the surrounding tissues, the surgeon's experience and additional internal diseases [8].

Many surgeons do not recommend surgical procedures for non-functional adrenal masses of $4 \mathrm{~cm}$ or less, considering the low malignancy rate [9]. Some authors recommend surgery for masses of $3 \mathrm{~cm}$ and over, while others recommend surgery for masses of $6 \mathrm{~cm}$ and over, while Linos et al. [10] argue that each patient should undergo adrenalectomy.

\section{CONCLUSION}

in tumors $6 \mathrm{~cm}$ and over was similar to the 20\% risk of malignancy in the current literature. The data obtained from the detailed examination also support the low malignancy rates of tumors $4 \mathrm{~cm}$ or less. We selected $4 \mathrm{~cm}$ as the limit for our clinical evaluation of patients with adrenal mass. Radiologically close follow-up in smaller masses; In the masses of $4 \mathrm{~cm}$ and above, we are in favor of making an operation decision.

\section{Conflict of interest}

The author disclosed no conflict of interest during the preparation or publication of this manuscript.

\section{Financing}

The authors disclosed that they did not receive any grant during conduction or writing of this study.

\section{REFERENCES}

1. Adler JT, Meyer-Rochow GY, Chen H, Benn DE, Robinson BG, Sippel RS et al. Pheochromocytoma: current approaches and future directions. Oncologist 2008;13:779-93.

2. Asari R, Koperek O, Niederle B. Endoscopic adrenalectomy in large adrenal tumors. Surgery 2012;152:41-9.

3. Favia G, Lumachi F, Basso S, D'Amico DF. Management of incidentally discovered adrenal masses and risk of malignancy. Surgery 2000;128:918-24.

4. Mantero F, Terzolo M, Arnaldi G. A survey on adrenal incidentiloma in Italy. Study group on adrenal tumors of the Italian Society of Endocrinology. J Clin Endocrinol Metab 2000;85:637644.

5. Moreira SG Jr, Pow-Sang JM. Evaluation and management of adrenal masses. Cancer Control 2002;9:326-34.

6 . Nieman LK. Approach to the patient with an adrenal incidentiloma. J Clin Endocrinol Metab 2010;95:4106-13.

7. Fassina AS, Borsato S, Fedeli U. Fine needle aspiration cytology (FNAC) of adrenal masses. Cytopathology 2000;11:302-11. 8. Erbil Y, Barbaros U, Aral F, Özbey N, İşsever H, Bozbora H, et al. [Transabdominal laparoscopic adrenalectomy: our clinical experience in 62 procedures]. Endokrinolojide Diyalog Dergisi 2008;4:181-7. [Article in Turkish]

9. Abdel-Aziz TE, Rajeev P, Sadler G, Weaver A, Mihai R. Risk of adrenocorticalcarcinoma in adrenal tumours greater than $8 \mathrm{~cm}$. World J Surg 2015;39:1268-73.

10. Linos DA, Stylopoulos N, Raptis SA. Adrenaloma: a call for more aggressive management. World J Surg 1996;20:788-93.

In our study, the rate of approximately $22 \%$ seen 